\title{
Humanitarian Principles: Laws Protecting Women and Children in Pakistan: A Critical Appraisal
}

\author{
${ }^{\text {a }}$ Saqib Jawad, ${ }^{\mathrm{b}}$ Barkat Ali, ${ }^{\mathrm{c}}$ Muhammad Hassan \\ a Civil Judge-Islamabad, Pakistan \\ Email: jawadsaqibjudge@gmail.com \\ ${ }^{\mathrm{b}}$ Assistant Professor, Department of Law, The Islamia University of Bahawalpur, Punjab, Pakistan \\ Email: barkatali27@gmail.com \\ ${ }^{c}$ PhD Fellow, Faculty of Law, University of Malaya, Malaysia \\ Email: hnsial@gmail.com
}

\begin{tabular}{l}
\hline ARTICLE DETAILS \\
\hline History: \\
Accepted 16 March 2021 \\
Available Online March 2021 \\
\hline Keywords: \\
Humanitarian; Principles; Rights, \\
Women; Children; Protection \\
JEL Classification: \\
Do3, J83
\end{tabular}

ABSTRACT

The principles which deal humanity are the core values of International Humanitarian Law (IHL) and Human Rights Law (HRL). Both of these codified laws expressly provide utmost protection for rights of women and children suffering war hostilities, armed conflicts and other natural disasters. These vulnerable groups are protected in the behest of International Law as well as Municipal laws. Indeed, it is admitted fact that during such crisis they become most vulnerable subject of the society. In this context, the statutory laws in Pakistan have also been promulgated in consonance with the IHL, HRL and Refugee Law. The main corpus of these rules has been embodied either directly or indirectly in the Constitution of Pakistan, 1973, and as such,

DOI: $10.47067 /$ real.v4i1.122 International Law have been ratified and thus is provisions are binding on Pakistan. However, it is observed that their applicability is not proper at state level, and as such they could not have provide effective remedies to the children and women in Pakistan. The aim of this research is to analyse critically, the applicability of Municipal Laws concerning with the protection of the rights of women and children in Pakistan, and for this objective, doctrinal research method has been adopted.

(C) 2021 The authors. Published by SPCRD Global Publishing. This is an open access article under the Creative Commons AttributionNonCommercial 4.0

Corresponding author's email address: jawadsaqibjudge@gmail.com

\section{Introduction}

Humanity and human sufferings remained co-related since the human history. Human sufferings may occur due to natural calamities, or man-made circumstances, such as war etc. However, endeavours are also made to prevent or at least curtail the human sufferings either of individual or collective nature. Therefore, protection of all humans' rights particularly of women and children, in armed conflict has proliferated under international law in the last three decades. Such special emphasis on women's and children's rights is because of their being the vulnerable subjects of the international 
community. Consequently, in international law context, there is now a wide range of international institutions engaged in defining, monitoring, and enforcing their rights in different adversities. The institutions like the International Committee of the Red Cross (ICRC), the International Criminal Court (ICC) and the United Nations Security Council (UNSC) are worth mentioning contributing a lot for redressing the human sufferings.

The increase in institutional activity is a broadly positive development. Nevertheless, there is significant scope to strengthen the legal status of specific protection of women and children. It is desirable, in fact to improve the role of pivotal institutions for implementing their guarantees with regard to their rights in different conflict settings. In this context, Islamic Republic of Pakistan (Pakistan) has also promulgated various statutory laws in the perspective of international obligations. However, their applicability is not satisfactory at state level, and in consequences, they do not confer ultimate remedies to the women and children. So the study undertaken intends to make a critical appraisal the reasons behind such failure, and the resolution thereof.

Therefore, this research critically analyses the applicability of municipal laws concerning the rights of women and children during hostilities and humanitarian actions. However, initially it elaborates the common salient features of various international organisations, being established for the protection of women and children during the hostilities. After that, it deliberates the developments of international law towards the protection of both of these vulnerable subjects and critically examines the applicability of domestic laws in Pakistan.

\section{Humanitarian Principles: Nature and Scope}

There are certain international organizations established to provide assistance to humans who fall victim of humanitarian crises. These organizations have also set up commonly certain principles to operate their actions with the aiming to halt human rights abuses. These principles are, namely, humanity, neutrality, impartiality and universality. These principles are followed for all types of massacres concerning human rights of the whole mankind including women and children. These principles are indeed to guide the work of humanitarian actors. (Haider, 2013) The nature and scope of such principles is discussed briefly under these lines.

The first humanitarian principle is the 'Humanity' or 'Humanitarian imperative' for securing the humans from sufferings. It is the fundamental principle of International Humanitarian Law (IHL). It means that everyone in need, have a right to assistance. The term 'everyone' includes women and children. (OCHA, 2013). The movement is primarily aimed to prevent human sufferings wherever they are found and to ensure their safety and health. (The Seven Fundamental Principles)

The 'Neutrality' is another principle of for humanitarian activities. IHL. It has been laid down that the impartiality will be observed beyond all types of controversy of social, political or religious nature, while humanitarian operations are in action for countering the humanitarian crises. (The Seven Fundamental Principles). The principle of 'Impartiality' is another standards parameter for securing the humanity from crises. It is central principle of humanitarian law of great importance for achieving real objectives of humanitarian actives carried on for addressing human crisis. It means that the movement for humanitarian actions shall carry on its operations on the basis of need alone, giving priority to the most urgent cases and shall make no discrimination as to sex, race, culture or religion. (The Seven Fundamental Principles).

The 'Universality' is another significant humanitarian principle. It says that movement, wherein 
all societies and countries have equal rights and responsibilities, is universal and shall not be restricted to a particular country or region. (The Seven Fundamental Principles).This principle, indeed, pledges that the movement is independent and shall not be guided by any political, religious, or social influence.

All these humanitarian principles have been either directly or indirectly are prescribed in in international laws and other legal documents. Principle of neutrality has been supported with the provisions of Additional Protocols I and II (AP-I\& II) which prescribe the conditions of impartiality and non-distinction for humanitarian actions. For instance, Article 70 of AP-I says that "relief actions... are humanitarian and impartial in character and conducted without any adverse distinction". Article 18 of AP-II says that "relief actions for the civilian population ...are of an exclusively humanitarian and impartial nature and which are conducted without any adverse distinction." (Plattner, 2010).

The Resolutions of the United Nations General Assembly (GA) also support these principles of humanity, neutrality and impartiality. The Resolution " $46 / 182$ of 19 December 1991 " proclaims that "humanitarian assistance must be provided in accordance with the principles of humanity, neutrality and impartiality". Some other resolutions on "strengthening the emergency humanitarian aid" also confirm these principles. International organizations and bodies have also provided the principles of humanity, impartiality, and neutrality. (Plattner, 2010). Additionally, national movements and organizations also operate and perform their functions in accordance with the principles set up by the movement. (The Seven Fundamental Principles).

\section{Humanitarian Principles in Pakistan}

With regard to the situation of humanitarian crises in Pakistan, people suffered due to a long lasting armed violence which began after 9/11 and its effects continue. Apart from that many natural calamities including earthquake and floods have been faced by the people of Pakistan. Law and order situation in the Province of Kheber Pakhtoonkhaw (KPK) and tribal areas has displaced millions of people. These people have suffered a lot particularly about necessities of life. Pakistan has a limited capacity to respond to these crises. International response also remained insufficient to cope with. However, Pakistan remained and continues to be the biggest operation area of ICRC and humanitarian movement. However, the ICRC and other organizations are also facing multiple challenges during their relief operations, particularly with regard to women and children, due to cultural and religious basis and these issues need to be addressed and responded timely. (McGoldrick, 2011).

Since Pakistan is a party to major human rights and humanitarian law instruments, so, certain obligations are also imposed on. Without going into the details, it is imperative to mention that Four Geneva Conventions of 1949 (GCs), their two Additional Protocols of 1977 and one of 2005 (APs) form the main corpus of IHL. Though, Pakistan is not party to AP II and III, but is party to four GCs and AP I, which is major portion of IHL. So, it has, to some extent, adopted measures to incorporate these provisions in the domestic law. Therefore, one of the views is that humanitarian law of women and children as mentioned in GCs and AP-I, is binding on Pakistan.

\section{Humanitarian Principles in International law}

Although, rights of women and children remained the primary concern HRL, but development in HRL had a great impact on IHL as well, particularly during last fifty years. During this period, movement for the rights of women and children got its momentum and main instruments of international law were adopted including the Convention on the Rights of the Child (CRC) and Convention on the Elimination of all Forms of Discrimination against Women (CEDAW). Governmental and Non-governmental organizations have specifically focused on the rights of women and children and 
endeavours are being made to develop effective mechanism for the implementation of these rights. (Gardam, 1998).

As far as IHL relating to women and children is concerned, references are found in earlier laws regarding protection of their rights, being vulnerable groups of the society. Women and children are not inherently vulnerable during an armed conflict because of the protection provided to them under all the legal systems. However, they become vulnerable and the most common issue is sexual violence against women during armed conflict and humanitarian action. (Colloquium, 214).

Certain measures have been taken in different national and international laws against sexual violence. Yet they are, broadly ineffective. For instance, if we look at historical laws, Article XLVII of the Leiber Code "provided punishment for rape of the inhabitants of a hostile country". However, sexual violence against women during armed conflict was not given due consideration until the twentieth century. Initially, rape was not considered a war crime at Nuremberg despite of high number of reported incidents. It was before the Tokyo tribunal when the charges of rape were levelled against certain individuals and few of them were also convicted on the ground that their subordinates did not obey the law. Although, offences were not prosecuted properly, but occupying powers included rape as a war crime in their Charters set up for trial of offences committed in Germany. (Colloquium, 214).

\section{Rights of Women and Children: Legal Development}

In the context of the above scenario, it was demanding that certain measures should be taken for protecting the women and children all over the world. Some prospective initiatives have been taken unanimously at various level in order to address the human rights abuse concerning this vulnerable class. So, the developments as happened in international as well as local laws, are critical examined under these lines.

\section{The Law of Nations \& Humanitarian Principles}

About 19 provisions from GCs and their two APs deal with protection of women and particularly they provide protection to pregnant and nursing women. They also provide safeguards to address the issue of sexual violence during armed conflict. For instance, Article 27 of GC IV deals with rape and provides that "women shall be especially protected against any attack on their honour, in particular against rape, enforced prostitution, or any form of indecent assault".

Though this provision is explicit in nature but it also contains twofold criticism. On the one hand it is alleged that this Article despite of recognizing rape as a violation of IHL, does not bring it within the grave breaches of international law, in respect of which states are obliged to punish the perpetrators. On the other hand, it is alleged that this Article does not contain any other prohibition including other forms of sexual violence. Article 76 of AP I provides the same nature of protection against rape but same problems lies with this provision. (Gardam, 1998).

Apart from that in 2000, "the 2000 Optional Protocol to the Convention on the Rights of the Child on the involvement of children in armed conflict" was adopted which prohibits the participation of children in armed conflict. This Protocol is also an example of combination of IHL and HRL. (Harland,). Many other provisions have been primarily incorporated to provide protection to children.

Therefore, it can safely be said that the protection provided to women and children lacks concrete measures. Although, scholars of international law have shown their concerns over the development of women's and child's rights in HRL. However, they are agreed that at least more 
progress has been made in HRL, as compared to IHL. Work of human rights and humanitarian organizations regarding protection of women in armed conflict is of considerable importance.

In this regard, ICRC is constantly dealing with the issue. Previously, women and children were included in the general categories of civilians even though they require different standards of protection as compared to general categories of civilians. After World War II, ICRC made efforts to protect the women prisoners of war. It was also suggested that women should be treated humanely during armed conflicts. (Gardam, 1998).

However, the aspect of sexual violence of women was ignored until the conflict of Yugoslavia, when sexual violence became visible and first time in the history of HRL and IHL, rape was included within the system of grave breaches. In this regard, ICRC in 1992 declared that the phrase "wilfully causing great suffering or serious injury to body or health" used in GCs and APs not only covered rape, rather any kind of attack on women's dignity and honour. Thus, first time these acts were considered punishable under the grave breaches of the Convention.

However, still it is said that to constitute an offence of rape within the parameters of Convention, it is required that such act is directed during an armed conflict against the civilian population as a whole and commission of the same on individual basis is not sufficient. Even then, the recognition of rape as crime in respect of grave breaches of IHL is a remarkable achievement of IHL. After the decision of Internal Criminal Tribunal of Yugoslavia, 1993, it is now difficult for any other administrative or judicial body to deny the inclusion of rape within the grave breaches of IHL.

Moreover, during the negotiations for the statute of International Criminal Court (ICC) inclusion of rape within the grave breaches of international law and serious violations of IHL as discussed in Common Article 3 to GCs (CA3) were also discussed. Other aspects including gender balance of court, protection of witnesses and victims and issue of sexual violence were also discussed. The Commission on the Status of Women in its March 1998 meeting, called on the States parties to support these measures.

Thereafter, ICRC focused on the women victims of armed conflicts which is apparent from different measures adopted in this regard. In 1993, during "the Final Declaration of the International Conference for the Protection of War Victims" it has shown serious concern over "the marked increase in acts of sexual violence directed notably against women and children". This issue was resolved that "such acts constituted grave breaches of international humanitarian law." Moreover, in 1995, during "the 26th International Conference of the Red Cross and Red Crescent" another resolution was adopted by consensus dealing with 'sexual violence against women'. Such practice was condemned, and it was suggested that these acts must be punished as war crimes and individuals involved in this process should be trained properly. (Gardam, 1998).

With regard to the rights of children, UNICEF is also endeavouring to ensure gender equality during humanitarian response. It means that men, women, boys and girls should have equal enjoyment of rights, values, opportunities, resources and rewards. (UNICEF, 2010). UNICEF has also undertaken many commitments with regard to child protection. These commitments include establishment of effective leadership for child protection, monitoring, reporting procedure, addressing the issue of separation of children from families during hostilities, violence, exploitation, psychosocial support, employment of children during armed conflict and issue of land mines. (UNICEF, 2010).

However, challenges include lack of humanitarian access, increasing disrespect of international 
law by the parties to the conflict and limited child protection capacity by the state concerned. (UNICEF, 2017). Therefore, for effective protection of child rights, these areas need to be focused and attempt to be developed more.

\section{Domestic Law of Pakistan\& Humanitarian Principles}

Pakistan is Islamic Republican State having a Constitution, 1973 claimed to be made for the welfare of the people of the country. However, a true sense of democracy and religion as well has been compromised in this regard. The main reason is that women themselves do not know about their rights. The most common problem rampant in Pakistan is discrimination and inequality with regard to women's rights. (Bhattacharya, 2014). Though more than twenty pro-women laws are available in Pakistan, but they are effective in urban areas only.

The situation of women in rural areas is deplorable and they face number of violations of their rights including "forced marriages, rape, vigilante justice, acid attacks, mutilations, honour killings, sawara, karokare and vani etc”.(Mushtaq,2014). The Constitution of Pakistan, 1973 explicitly prohibits any discrimination and states that, "There shall be no discrimination on the basis of sex along."(Article, 25); "Steps shall be taken to ensure full participation of women in all spheres of national life."(Article, 34); "the state shall protect the marriage, the family, the mother and the child." (Article, 35).

However, despite of these constitutional guarantees, rights of women are being violated openly. According to a survey conducted in 2011 by "the Thomson Reuters Foundation", "Pakistan is the third most dangerous country for women”. (Bhattacharya, 2014, 182). The challenges with regard to the enforcement of women's rights can be categorized into intrinsic and extrinsic. Intrinsic challenges are those which are inherited in human nature, like attitude. Whereas, extrinsic factors surround a person and influence him externally, such like, culture, religion and the relevant law. (Muneer, 2018).

For the rights of children, under IHL, the most common issue is recruitment of children during armed conflict. In this regard, Article 38 of the Convention on the Rights of the Child provides that "states parties shall refrain from recruiting children under fifteen years and that among those who have attained the age of fifteen years but who have not attained the age of eighteen years, States Parties shall give priority to the oldest".

In 2001, Pakistan also signed the Optional Protocol on Children in Armed Conflict. It asserts that "states parties shall do the possible in order that members of their armed forces who have not attained the age of eighteen years do not take a direct part in hostilities". In this regard, the Pakistan National Service Ordinance of 1970 provides that the age for recruitment in the armed forces of Pakistan is eighteen years with the possibility of two years prior training. Thus, the rules for recruitment in the armed forces of Pakistan are in conformity with the rules of international law prescribed in the Convention on the Rights of the Child and the Optional Protocol on Children in Armed Conflict.

Instead of the above protective measures, certain armed groups and some organizations are reported to have recruited children for conducting hostile actions against the state and other armed groups. Concrete measures in this regard are required to be taken, because international law imposes certain obligations on the states as well as such armed groups. Article 4 (1) of the Optional Protocol in this context provides that "armed groups that are distinct from the State's armed forces should not, under any circumstances, recruit or use in hostilities persons under the age of 18 years." Article 4 (2) further imposes obligations on the states by providing that the states are under obligation to "take all feasible measures to prevent such recruitment and use, including the adoption of legal measures to 
prohibit and criminalize such practices." (Berti, 2003, 5-6).

For child protection during humanitarian action, three bodies of international law work together which are IHL, HRL and refugee law. Combination of rules prescribed in these bodies of laws gives four types of minimum standards for child protection during humanitarian action and those include, "Survival and development, non-discrimination, child participation and the best interest of the child." (CPWG, 2012, 15).

As stated earlier, Pakistan is party to GCs and AP I and thus, it is claimed that the rules mentioned in these instruments are binding on Pakistan under the regime of international law. Pakistan also faced the issue of insurgency and armed conflict during last three decades and particularly after 9/11. During the first five years after 9/11, a "full-blown" armed conflict was witnessed in the province of KPK, Federally Administered Tribal Areas (FATA) and Provincially Administered Tribal Areas (PATA). (Khan, 2009). Some international law experts believe that keeping in view the Tadic test, situation of tribal areas of Pakistan has reached the required threshold of an armed conflict. (Soofi, et al, 28). It is also claimed that role of women remained a central dispute and core issue of this conflict. They are prevented from attending schools and restricted from going outside homes. It further led to burning girls' schools and publically punishing women accused of immoral activities.

These acts were in explicit contravention of Pakistan's commitments to the principles of IHL and HRL at international level and these violations were reported to the government of Pakistan by various humanitarian organizations as early as 2007. In consequence of conflict, Internally Displaced Persons (IDPs) were placed at temporary shelters where children were exposed to abuse, kidnapping and abduction. This conflict has also made women vulnerable. In this regard Yakin Ertuk, the UN Special Rapporteur on violence against women, is reported to observe that, "women's vulnerability increases manifold when they do not have adequate and safe housing, cannot access water, lose their privacy, live in close proximity to unrelated men, are exhausted, at risk of sexual violence, and, to make matters even worse, are excluded from decision-making." (Khan, 2009, 20).

The Constitution of Pakistan, 1973 is supreme law of the land which deals with the rights of women and children and its' chapters 1 and 2 of Part II is dealing with the fundamental rights and principles of policy. As stated earlier, Article 25 and 34 of the Constitution specifically deal with the rights of women. Apart from that, number of domestic legislations are available, which are though not promulgated on humanitarian principles, but protect the rights of women. As far as issue of implementation of women's and child's rights is concerned, number of domestic and international instruments though deal with the issue but they do not provide ultimate remedy for the rights of these vulnerable groups, but provide a road map which can be followed and can be made more effective with certain other measures.

In this regard, certain criminal laws, including, The Acid Control and Acid Crime Prevention Act, 2011, Prevention of Anti-Women Practices Act, 2011, Criminal Law (Amendment) (Offense of Rape) Act 2016, Criminal Law (Amendment) (Offences in the name or pretext of Honour) Act, 2016, and certain other general laws on the protection of women have been promulgated at provincial levels which include Punjab Women Protection Authority Act, 2017, Punjab Protection of Women against Violence Act, 2016, Punjab Fair Representation of Women Act, 2014, and The Punjab Protection against Harassment of Women at the Workplace (Amendment) Act, 2012.

Moreover, with regard to laws of child, Juvenile justice System Act 2018 is the recent legislation 
which replaced Juvenile justice System Ordinance 2000 and provides certain legal guarantees to the children but even after promulgation of this Act, juvenile Courts have not been separated in various provinces and the Islamabad Capital territory. In the province of Punjab, Punjab Restriction on Employment of Children Act, 2016 and Punjab Prohibition of Child Labour at Brick Kilns Act, 2016, have been promulgated, but again these laws have not been implemented in their entirety.

Thus, we can say that various national legislations are available which directly or indirectly deal with the rights of women and children during humanitarian crises and humanitarian action, but implementation of these laws is the main problem which makes them vulnerable. Time and again, members of civil society and human rights activists have called for implementation of these laws. (Qadir, 2018). Another concern has been shown by various experts that these laws were never promulgated keeping in view the needs and problems of indigenous society. Lawmakers lack concerns and commitments. It is also claimed that mostly these laws are passed without proper research, attention and professionalism. (IPS, 2011).

Pakistan is also bound under various international commitments. Starting with the UDHR, Pakistan is party to number of international Conventions which obligate to protect the rights of women and children. In this regard, among other measures, certain Conventions have developed a reporting procedure. In this regard, number of reports have been prepared and in 1997 the report of the Commission of Inquiry for Women was prepared under the leadership of Justice Ret. Nasir Aslam Zahid, which emphasised on the rights of women pertaining to food, shelter, education, health, sanitation and training for employment as developing rights and proposed that it is the primary responsibility of the state to provide and protect these rights. Moreover, it has also been proposed that these rights available in international instruments need to be interpreted keeping in view the guarantees available in the Constitution of Pakistan to avail their full applicability.

Since Pakistan is a dualist country and despite of signing various international instruments, did not take measures for their implementation, therefore, it is said that these instruments are not yet legally binding on Pakistan. Another view is that various principles enunciated in these instruments have been promulgated in the Constitution, hence, they are binding. This argument is supported with the GoP reports submitted to CEDAW Committee in 2006-07 and to the Human Rights Council in 2008. (Khan, 2009). After participating in 1995 Conference, Pakistan formulated a National Plan of Action which focused on "poverty, health, violence, armed conflict, and the human rights of women”.

Thus, it can be said that though no specific humanitarian law on women and children has been promulgated and the entire reliance is on the judicial interpretations of the rights available in the Constitution and other domestic laws. Laws on some human rights are though promulgated but lack rules of procedure, making them incapable for implementation. Though, some judgments have been given with regard to the protection of these rights but the main focus is on individual cases or issues in hand and judiciary could not adopt a clear rights based approach. Moreover, lack of training and understanding of reasoning of courts also make the matter more complex. Therefore, promulgation of statutory laws in accordance with the needs of the time and keeping in view the requirements of our society is imperative. (Khan, 2009).

\section{Conclusion}

During the last century, remarkable achievements have been made in the fields of IHL and HRL, but international law experts and human rights activists have still shown their concerns in this regard and more particularly with regard to the protection of rights of women and children. Despite of 
repeated calls by human rights organizations, the required standard of protection could not be incorporated at international and domestic level. Therefore, a lot is yet to be achieved in this regard. Moreover, rules prescribed under IHL and HRL lack proper implementation at domestic level, because most of the countries, including Pakistan, have not yet taken any concrete measures for their proper implementation. Hence, effective mechanism for enforcement of these rights at domestic level is required and it should be made clear that mere insertion of these rights in some domestic legal instruments would not suffice, unless the standard of protection afforded to women and children is achieved, either through legislation or through clear rights based judicial interpretations.

\section{References}

Bhattacharya, Sanchita. (2014). Status of Women in Pakistan. J.R.S.P., Vol. 51, No. 1. (179- 211).

Berti, Stefano. (2003). Rights of the Child in Pakistan. Committee on the Rights of the Child 34th Session - Geneva, OMCT.

CPWG. (2012). Minimum standards for child protection in humanitarian action. Child Protection Working Group.

Soofi, Ahmer, B., Sultan, A., Aziz J., Rizvi A., and Qaisrani. Fahd, H. (2015). The Legal Implications of Adopting a Conflict Paradigm in Pakistan. Research Society of International Law, Pakistan, 28.

Gardam, Judith (1998). Women, human rights and international humanitarian law. International Review of the Red Cross, No. 324. Retrieved from https://www.icrc.org/en/doc/resources/documents/article/other/57jpg4.htm

Haider, Huma. (2013). International legal framework for humanitarian action. Birmingham: GSDRC.

Harland, Christopher. The Domestic Implementation and Application of International Humanitarian Law Norms. ICRC Advisory Service on IHL, Geneva, Switzerland.

ICRC - EUISS, (2014). Women and War, Women \& Armed Conflicts and the Issue of Sexual Violence. Retrieved from www.icrc.org

IPS Task Force. (2011). Legislation on 'Women and family' in Pakistan- Trends and Approaches-II. Policy Perspectives, Vol. 8, No. 1 (97-124).

Khan, Rabia. (2009). Situational Analysis and Mapping of Women's Human Rights in Pakistan, CIDA Pakistan Program, Retrieved from http://www.researchcollective.org/Documents/Final\%2oReport_on_Women.pdf

McGoldrick, C. (2011). The future of humanitarian action: an ICRC perspective International Review of the Red Cross, Volume 93, No. 884. (965-991).

Muneer Sania. (2018) Pro-women Laws in Pakistan: Challenges towards Implementation. Pakistan Vision Vol. 18 No. 2. (86-101).

Mushtaq, Asma and Razzaq, Munazza and Omar, Shagufta (2014). Constitutional and Legal Rights of Women in Pakistan. Ameena Suhail, ed. Women Aid Trust, Pakistan, Retrieved from https://ssrn.com/abstract $=2484371$

OCHA. (2013).Humanitarian Principles in Brief. Retrieved from https://www.gsma.com/mobilefordevelopment/wp-content/uploads/2013/o7/UN-OCHAHumanitarian-Principles-in-Brief.pdf

Plattner, Denise. (2010). ICRC neutrality and neutrality in humanitarian assistance. International Review of the Red Cross, Volume 36, Issue No. 11. (1961-1997).

Qadir, Ihsan. (2018, September 11). Activists call for enforcement of women, child protection laws. Pakistan Today, Retrieved from https://archive.pakistantoday.com.pk/2018/o9/11/activists-callfor-enforcement-of-women-child-protection-laws/

The Geneva Convention Relative to the Protection of Civilian Persons in Time of War. (1949). Fourth Geneva Convention. Retrieved from https://www.un.org > Doc.33_GC-IV-EN.pdf 
The Protocol Additional to the Geneva Conventions of 12 August 1949 and relating to the Protection of Victims of International Armed Conflicts (Protocol I), 8 June 1977.

The Constitution of Islamic Republic of Pakistan, 1973.

The Seven Fundamental Principles, International Federation of Red Cross and Red Crescent Societies, Retrieved from https://www.ifrc.org/who-we-are/vision-and-mission/the-seven-fundamentalprinciples/

UNICEF (2010). Core Commitments for Children in Humanitarian Action. UNICEF, New York, 6-7.

UNICEF to the OHCHR. (2017). Protecting the Rights of the Child in Humanitarian Situations. Retrieved from https://www.ohchr.org/Documents/Issues/Children/HumanitarianSituations/UNICEF.pdf 